\title{
Formation Mechanism of Alkyl Nitrites, Valuable Intermediates in C1-Upgrading Chemistry and Oxidation Processes
}

\author{
Ive Hermans • Joaquim Henrique Teles $\cdot$ Richard Dehn • \\ Till-Christian Brüggemann • Robert Send · \\ Philipp Nikolaus Plessow
}

Published online: 12 July 2014

(C) Springer Science+Business Media New York 2014

\begin{abstract}
In this contribution we use computational tools to investigate the reaction of alcohol substrates with reactive nitrogen oxide species such as $\mathrm{N}_{2} \mathrm{O}_{3}$ and $\mathrm{N}_{2} \mathrm{O}_{4}$, leading to the formation of alkyl nitrites. These nitrites are interesting intermediates which can be processed to various valuable chemicals such as ketones/aldehydes and dimethyl oxalate while regenerating $\mathrm{NO}_{x}$. As such, $\mathrm{NO}_{x}$ is used as an oxidation mediator, converting alcohol substrates to more reactive nitrites which can be selectively converted to more desired compounds, closing a catalytic cycle in $\mathrm{NO}_{x}$ species.
\end{abstract}

Keywords Alcohol oxidation - Mechanism · Computational prediction $\cdot \mathrm{NO}_{x} \cdot$ Syngas upgrading

\section{Introduction}

\subsection{Background}

Ethylene glycol (EG) is industrially produced by the liquidphase hydration of ethylene oxide, which is obtained by the

\footnotetext{
I. Hermans $(\bowtie)$

Department of Chemistry and Applied Biosciences, ETH Zurich,

Wolfgang-Pauli-Strasse 10, 8093 Zurich, Switzerland

e-mail: hermans@chem.wisc.edu
}

Present Address:

I. Hermans

Departments of Chemistry and Chemical and Biological

Engineering, University of Wisconsin - Madison,

1101 University Avenue, Madison, WI 53706, USA

J. H. Teles · R. Dehn - T.-C. Brüggemann - R. Send ·

P. N. Plessow

BASF SE, 67056 Ludwigshafen, Germany aerobic epoxidation of ethylene over a silver catalyst [1]. In 2009, the production of EG was estimated at 1.45 million metric tons. About $75 \%$ of this is used in the production of polymers of which polyethylene terephthalate (PET) is the largest application. This traditional value-chain is being challenged by a newly developed syngas-based route, outlined in Scheme 1 [2-10]. The process consists of three sequential steps: (i) the synthesis of methyl nitrite from methanol (ii) the catalytic carbonylation of methyl nitrite to dimethyl oxalate over a heterogeneous palladium catalyst, and (iii) the catalytic hydrogenation of the dimethyl oxalate to EG over a copper catalyst, regenerating methanol. Overall this process results in the oxidative upgrading of syngas to EG using catalytic amounts of nitrogen(II)oxide. In view of the growing naphtha prices and cheap feedstocks for the production of syngas, such as coal in China and shale gas in the USA, this alternative approach becomes very attractive. Currently, already six EG plants using this technology-originally developed by UBE in Japan - are under construction, each around 200,000 t/year capacity [11]. Methyl nitrite is the crucial intermediate on which this technology depends. Its synthesis can be achieved by contacting liquid methanol with nitrogen oxides $\left(\mathrm{NO} / \mathrm{NO}_{2}\right)$ [12-18]. Counter-current columns with different packing material, or spray towers have been described in the (patent) literature for this gas-liquid reaction [19].

Alkyl nitrites also play a crucial role in other areas of oxidation catalysis. Recently, some of us showed that alkyl nitrites featuring an $\alpha \mathrm{H}$-atom $\left(\mathrm{RCH}_{2} \mathrm{ONO}\right)$ undergo Brønsted acid-catalyzed decomposition to the corresponding carbonyl product plus HNO [20]. HNO is a reactive species which dimerizes very fast to yield water and $\mathrm{N}_{2} \mathrm{O}$. In the presence of $\mathrm{NO}_{2}, \mathrm{HNO}$ is transformed to $\mathrm{NO}$ plus $\mathrm{HNO}_{2}$. This molecular mechanism is at the basis of a 
Scheme 1 The traditional (above) and new (below) ethylene glycol routes

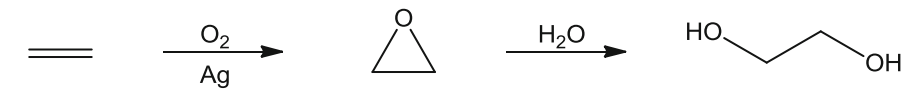

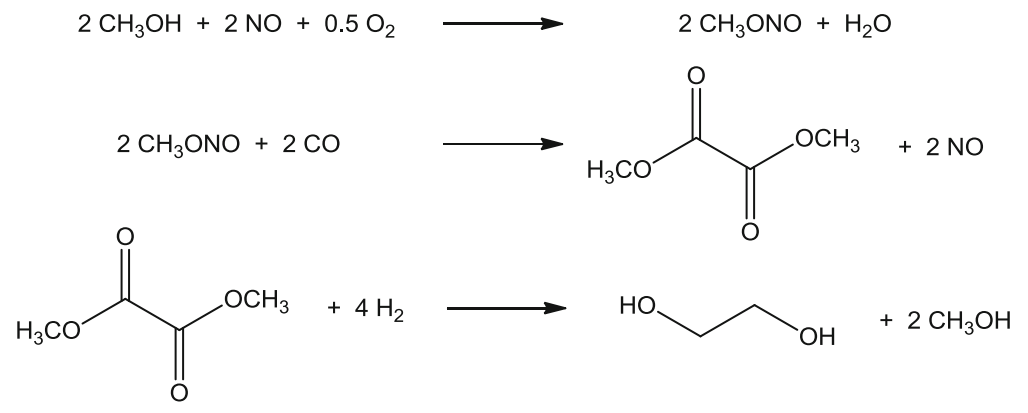

$2 \mathrm{CO}+4 \mathrm{H}_{2}+0.5 \mathrm{O}_{2}$
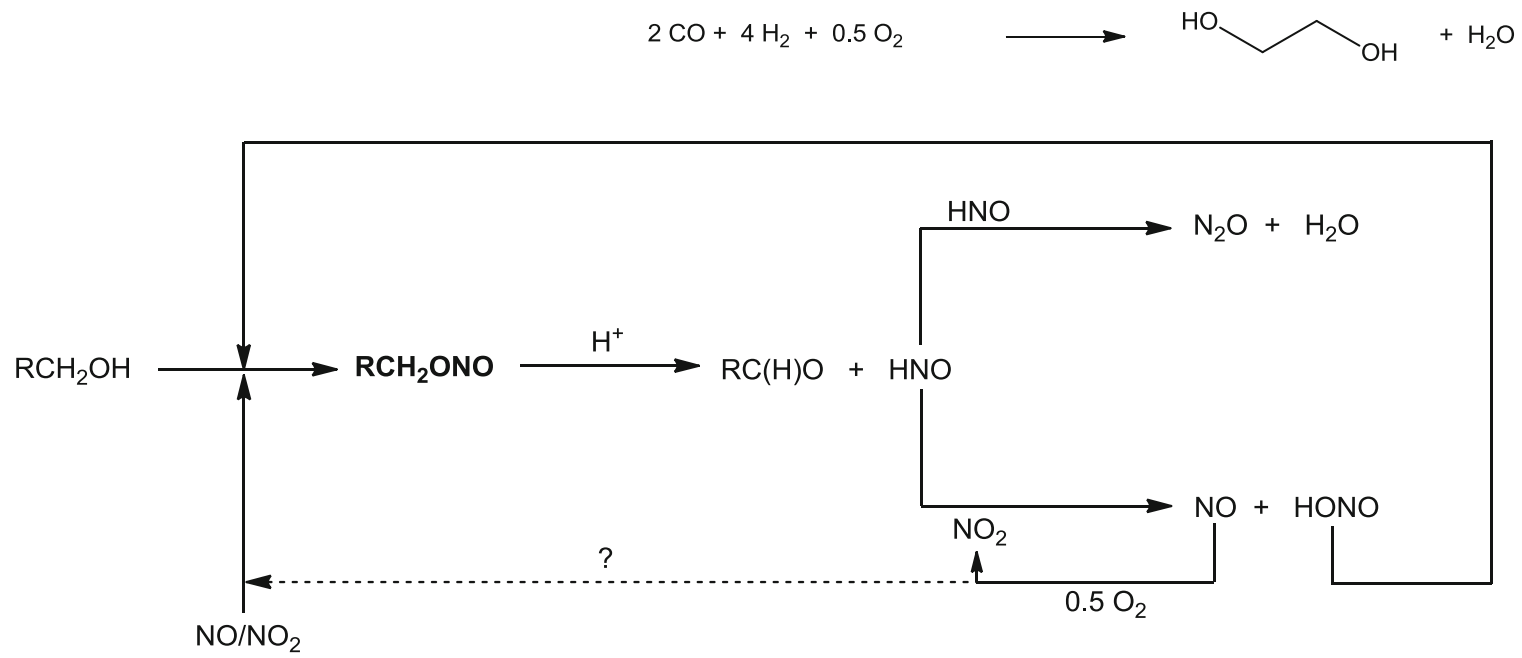

Scheme 2 The role of alkyl nitrite as intermediate in the $(\mathrm{H}) \mathrm{NO}_{y}$-mediated aerobic alcohol oxidation

recently proposed aerobic alcohol oxidation system (see Scheme 2) [21]. The $\mathrm{HNO}_{2}$ can react with the alcohol substrate to form additional nitrite, and the NO can be oxidized to $\mathrm{NO}_{2}$ with molecular oxygen, closing a catalytic cycle in $(\mathrm{H}) \mathrm{NO}_{y}$ species. Those $(\mathrm{H}) \mathrm{NO}_{y}$ species can be supplied to the reactor as $\mathrm{HNO}_{3}$, or $\mathrm{NO}_{x}$. Also in this system, alkyl nitrites are crucial intermediate species. Although they can be formed via the (acid-catalyzed) esterification of the alcohol substrate with $\mathrm{HNO}_{2}$, a direct reaction of the alcohol with the $\mathrm{NO}_{x}$ species as in the methyl nitrite synthesis described above cannot be excluded.

Based on this reaction mechanism, it is clear that one needs to maintain a high $\mathrm{NO}_{2}$ concentration to avoid the undesired formation of $\mathrm{N}_{2} \mathrm{O}$ (viz., kinetic competition for $\mathrm{HNO}$ ). As $\mathrm{NO}_{2}$ is known to react readily with $\mathrm{H}_{2} \mathrm{O}$, we constantly removed the water from the reaction solution by re-circulating the gas phase over a fixed-bed of molecular sieves. As $\mathrm{NO}_{2}$ prefers to remain in the liquid phase, this approach allows the selective removal of $\mathrm{H}_{2} \mathrm{O}$ while not trapping the $\mathrm{NO}_{2}$ [21]. Although this approach resulted in a significant increase in reaction rate and minimized the formation of $\mathrm{N}_{2} \mathrm{O}$, leading to a higher end conversion, it is not very practical as after awhile one would need to regenerate the adsorber. Therefore, the use of a continuous flow setup (Fig. 1) was subsequently investigated [22]. In that system, a segmented flow of alcohol/ $/ \mathrm{HNO}_{3}$ plus oxygen is fed to a fixed-bed reactor, packed with the solid Brønsted acid catalyst Amberlyst- $15^{\circledR}$. It was found that full conversion could be achieved within very short contact times without the need to remove water. At a given alcohol conversion level, significantly less $\mathrm{N}_{2} \mathrm{O}$ formation was observed in this three-phase flow system, compared to a batch reactor setup. 


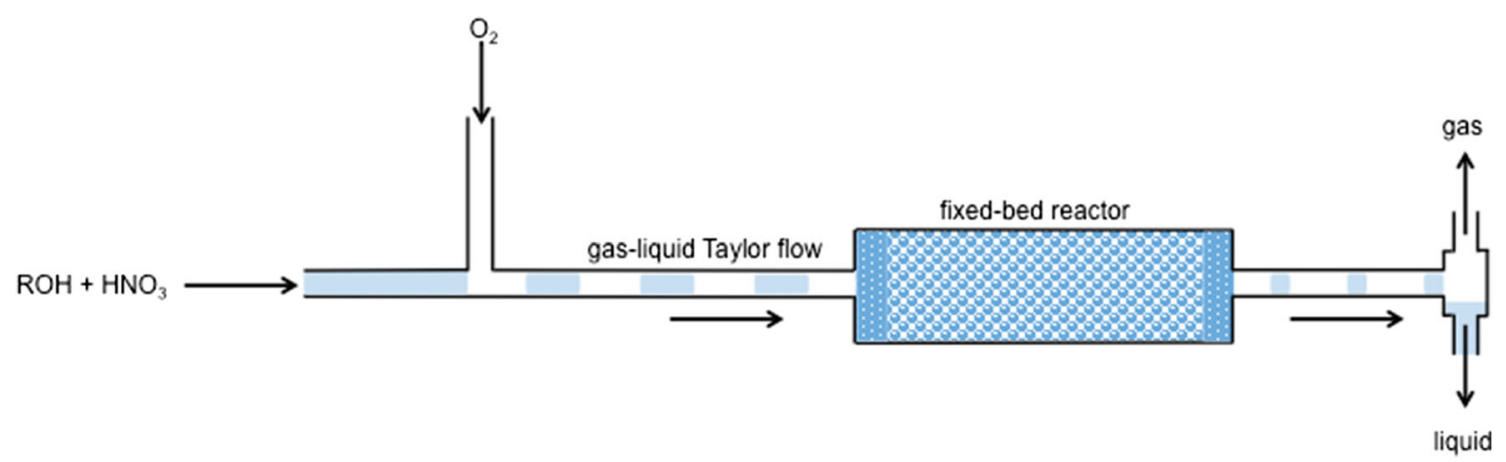

Fig. 1 Continuous flow setup for the aerobic oxidation of alcohols with catalytic amounts of $\mathrm{HNO}_{3}$

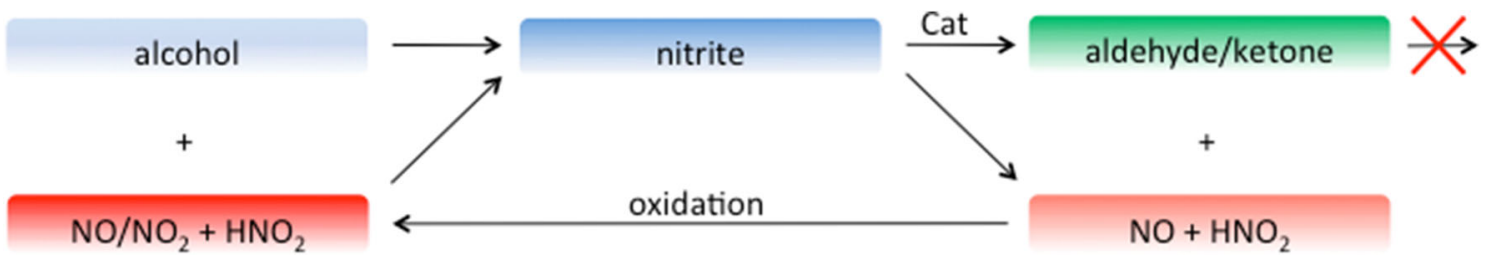

Fig. 2 Concept of pre-activating an alcohol substrate to a reactive nitrite which can be catalytically decomposed to the desired aldehyde/ketone. Since the carbonyl group cannot be activated under the reaction conditions, over-oxidation of the primary product is avoided

This system allows to alter the intrinsic selectivity issue in alcohol oxidation catalysis. Although the oxidation products (aldehydes/ketones) are intrinsically more oxidizable than the alcohol substrate, due to the milder reaction conditions they are protected from over-oxidation, because the carbonyl products cannot form the reactive nitrite species (Fig. 2).

As a next development one could envision starting with an $\mathrm{NO} / \mathrm{NO}_{2}$ mixture rather than $\mathrm{HNO}_{3}$ to generate the $(\mathrm{H}) \mathrm{NO}_{y}$ species. The precise formation of the crucial alkyl nitrite intermediate from alcohol and $\mathrm{NO}_{x}$ will be key to optimize the reaction conditions in terms of the required amount of $\mathrm{NO}_{x}$ (viz., to increase the catalytic turnover efficiency in $\mathrm{NO}_{x}$ ).

\subsection{Outlook}

The observations outlined above prompt us to look more carefully at the $\mathrm{NO}_{x}$ reactions with alcohols, forming alkyl nitrites. Of particular interest is the nitrosation reaction with $\mathrm{N}_{2} \mathrm{O}_{3}$, a reaction known to produce harmful $N$-nitrosoamines with amines [23]. Dinitrogen trioxide is a well-known reactive nitrogen oxide species (RNOS) like dinitrogen tetraoxide $\left(\mathrm{N}_{2} \mathrm{O}_{4}\right)$. The structural isomers of $\mathrm{N}_{2} \mathrm{O}_{3}$ and $\mathrm{N}_{2} \mathrm{O}_{4}$, formed upon the equilibrium reaction of $\mathrm{NO}_{2}$ with $\mathrm{NO}$ and $\mathrm{NO}_{2}$, respectively, are well investigated, and the most stable structures are summarized in Scheme 3. $\mathrm{N}_{2} \mathrm{O}_{3}$ exists in an asymmetric $\mathrm{N}-\mathrm{N}$ coupled isomer $\mathbf{1}$, a symmetric isomer $\mathbf{2}$ and a trans-cis isomer $\mathbf{3}$. In addition to these most stable isomers, significantly less stable isomers have been reported [24] $\mathrm{N}_{2} \mathrm{O}_{4}$ exists in a symmetric isomer $\mathbf{4}$, and a trans- and cis-conformer $\mathbf{5}$ and $\mathbf{6}$, respectively [25].

Our aim is to provide insights in the reaction mechanism of the nitrosation reaction using quantum chemical calculations. The reactivity of the different isomers, the influence of the alcohol structure, as well as the solvent polarity will be addressed.

\section{Methods}

All calculations were performed with the Gaussian 09 (revision A.02) program package [26]. Frequency analyses and intrinsic reaction coordinate (IRC) calculations identified stationary points on the potential energy surfaces (PESs) as true minima or as transition states (TSs) connecting reactants and products. An open-shell singlet initial guess was used for all calculations. After obtaining the reaction paths at the B3LYP-DFT level of theory [27-29], other methods were used for comparison (e.g., $\omega B$ 97-DFT [30] and QCISD [31] ) or refinement (e.g., CBS-APNO [32] and single point $\operatorname{CCSD}(\mathrm{T})$ [33, 34] calculations). Unless explicitly mentioned, the $6-311++\mathrm{G}(\mathrm{df}, \mathrm{pd})$ basis set was used. All reported relative energies have been corrected for zero point energy (ZPE). 
Scheme 3 The most stable isomers of $\mathrm{N}_{2} \mathrm{O}_{3}(\mathbf{1}-\mathbf{3})$ and $\mathrm{N}_{2} \mathrm{O}_{4}$ (4-6) formed upon reaction of $\mathrm{NO}_{2}$ with $\mathrm{NO}$ and $\mathrm{NO}_{2}$, respectively

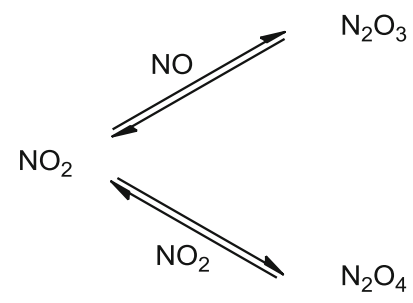

$\mathrm{N}_{2} \mathrm{O}_{3}$

$\mathrm{N}_{2} \mathrm{O}_{4}$<smiles></smiles>

1<smiles></smiles>

4

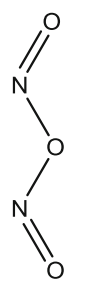

2<smiles></smiles>

5<smiles>O=NON=O</smiles><smiles></smiles>

\section{Results and Discussion}

\subsection{Stability of the $\mathrm{N}_{2} \mathrm{O}_{3}$ and $\mathrm{N}_{2} \mathrm{O}_{4}$ Isomers}

The stability of the different $\mathrm{N}_{2} \mathrm{O}_{3}$ and $\mathrm{N}_{2} \mathrm{O}_{4}$ isomers is compared at different levels of theory in Table 1. Earlier work by Liu and Goddard [25] showed that the large resonance energy in $\mathrm{NO}_{2}$ has a dramatic effect on the stability of the different $\mathrm{N}_{2} \mathrm{O}_{4}$ dimers. Comparing their most reliable RCCSD(T)/CBS results with various DFT and single point methods, clearly indicates that the B3LYP predicted stability deviates substantially from the state-of-the-art methods such as CCSD(T)//QCISD, CBS-APNO and RCCSD(T)/CBS. The results obtained with the $\omega \mathrm{B} 97$ functional, including long range corrections, fall between the benchmark results. Irrespective of the method, it is clear that the symmetric dimer 4 is by far the most stable one. Goddard et al. predicted that the formation of 4 and 6 from the two separate $\mathrm{NO}_{2}$ constituents proceeds without a barrier, or with a very low barrier, respectively. The combination of two $\mathrm{NO}_{2}$ species to form the trans isomer 5 would feature a barrier of around $13 \mathrm{kcal} \mathrm{mol}^{-1}$. Although the symmetric isomer $\mathbf{4}$ can isomerize to the trans isomer $\mathbf{5}$, the reaction faces a thermally inaccessible barrier of $45 \mathrm{kcal} \mathrm{mol}^{-1}$. A more plausible pathway to 5 would be isomerization of $\mathbf{6}$, featuring a barrier of less than $3 \mathrm{kcal} \mathrm{mol}^{-1}$. Unimolecular breakup of the symmetric $\mathrm{N}_{2} \mathrm{O}_{4}$ dimer would face a barrier of around $16.5 \mathrm{kcal} \mathrm{mol}^{-1}$. All these computational predictions seem to imply a fast interconversion of the various $\mathrm{N}_{2} \mathrm{O}_{4}$ and $\mathrm{NO}_{2}$ species under relevant reaction conditions. A similar situation is encountered for the $\mathrm{N}_{2} \mathrm{O}_{3}$ dimer (Table 1). Isomers $\mathbf{1}$ and $\mathbf{2}$ are predicted to be more or less equally stable, in line with experimental evidence [35-37], whereas the trans-cis isomer $\mathbf{3}$ would be $\mathbf{3}-\mathbf{4} \mathrm{kcal} \mathrm{mol}^{-1}$ higher in energy. Fast isomerization can occur though breakup of the isomers in $\mathrm{NO}$ plus $\mathrm{NO}_{2}$, and subsequent recombination [24].

We emphasize that the relative stability of the various isomers, or their thermal population for that matter, does not imply their kinetic reactivity towards substrates. The reactivity of the various $\mathrm{N}_{2} \mathrm{O}_{3}$ and $\mathrm{N}_{2} \mathrm{O}_{4}$ isomers towards methanol is addressed in the next paragraph.

\subsection{Nitrosation of Methanol With $\mathrm{N}_{2} \mathrm{O}_{3}$ and $\mathrm{N}_{2} \mathrm{O}_{4}$}

Scheme 4 illustrates how the various $\mathrm{N}_{2} \mathrm{O}_{3}$ isomers can react with methanol. Whereas all isomers lead to the formation of the alkyl nitrite $\mathrm{CH}_{3} \mathrm{ONO}$, isomers $\mathbf{1}$ and $\mathbf{3}$ coform $\mathrm{HONO}$, while isomer 2 yields $\mathrm{H}-\mathrm{NO}_{2}$. The latter product will rapidly isomerize to the more stable HONO, either unimolecularly, or catalyzed by an $\mathrm{NO}_{2}$ molecule (i.e., via $\mathrm{H}$-abstraction by $\mathrm{NO}_{2}: \mathrm{NO}_{2}+\mathrm{H}-\mathrm{NO}_{2} \rightarrow \mathrm{HONO}$ $+\mathrm{NO}_{2}$ ).

Table 2 summarizes the adiabatic barriers of the reactions in Scheme 4. Although B3LYP-DFT seems to qualitatively predict the reactivity trend of the three isomers, it fails quantitatively (viz., deviations by more than $5 \mathrm{kcal} \mathrm{mol}^{-1}$ compared to $\operatorname{CCSD(T)//QCISD~level~of~}$ theory). One possible reason for this is the absence of longrange dispersion interactions for the B3LYP functional. This seems to be confirmed by the fact that the $\omega \mathrm{B} 97$ results agree rather well with more advanced methods. These predictions indicate that the least stable isomer $\mathbf{3}$ is the most reactive one and will contribute most to the reaction flux (i.e. most of the $\mathrm{N}_{2} \mathrm{O}_{3}$ formed through combination of $\mathrm{NO}$ plus $\mathrm{NO}_{2}$ will react with methanol via isomer 3).

To further substantiate this reactivity difference, we used transition state theory (TST) to predict the fate of thermalized $\mathrm{N}_{2} \mathrm{O}_{3}$. Using the QCISD-predicted geometry and B3LYPpredicted vibrational parameters, rotational-vibrational 
Table 1 Relative stability of the various $\mathrm{N}_{2} \mathrm{O}_{3}$ and $\mathrm{N}_{2} \mathrm{O}_{4}$ isomers at various levels of theory

\begin{tabular}{|c|c|c|c|c|c|c|c|}
\hline Structure & B3LYP & $\mathrm{CCSD}(\mathrm{T}) / / \mathrm{B} 3 \mathrm{LYP}$ & $\omega \mathrm{B} 97$ & $\operatorname{CCSD}(\mathrm{T}) / / \omega \mathrm{B} 97$ & CBS-APNO & $\operatorname{CCSD}(\mathrm{T}) / / \mathrm{QCISD}^{\mathrm{a}}$ & $\operatorname{RCCSD}(\mathrm{T}) / \mathrm{CBS}[25]$ \\
\hline $\mathrm{N}_{2} \mathrm{O}_{3} \mathbf{1}$ & 0.0 & 0.1 & 1.0 & 0.4 & 0.0 & 0.5 & \\
\hline $\mathrm{N}_{2} \mathrm{O}_{3} 2$ & 3.35 & 0.0 & 0.0 & 0.0 & 0.0 & 0.0 & \\
\hline $\mathrm{N}_{2} \mathrm{O}_{3} 3$ & 6.6 & 4.9 & 4.2 & 3.9 & 3.5 & 3.8 & \\
\hline $\mathrm{N}_{2} \mathrm{O}_{4} 4$ & 0.0 & 0.0 & 0.0 & 0.0 & 0.0 & 0.0 & 0.0 \\
\hline $\mathrm{N}_{2} \mathrm{O}_{4} 5$ & 10.9 & 6.6 & 7.1 & 6.2 & 6.85 & 6.1 & 8.6 \\
\hline $\mathrm{N}_{2} \mathrm{O}_{4} 6$ & 13.4 & 9.6 & 9.9 & 8.7 & 8.95 & 8.35 & 10.6 \\
\hline
\end{tabular}

${ }^{a}$ Geometry optimized at QCISD/6-311++G(d,p) level; ZPE correction at B3LYP/6-311++G(df,pd) level single point energy calculation at $\operatorname{CCSD}(\mathrm{T}) / 6-311++\mathrm{G}(\mathrm{df}, \mathrm{pd})$ level

Scheme 4 Reaction of the $\mathrm{N}_{2} \mathrm{O}_{3}$ dimer species with methanol. Distances in Ångstrom and angles in degree as optimized at the QCISD/6$311++\mathrm{G}(\mathrm{d}, \mathrm{p})$ level of theory
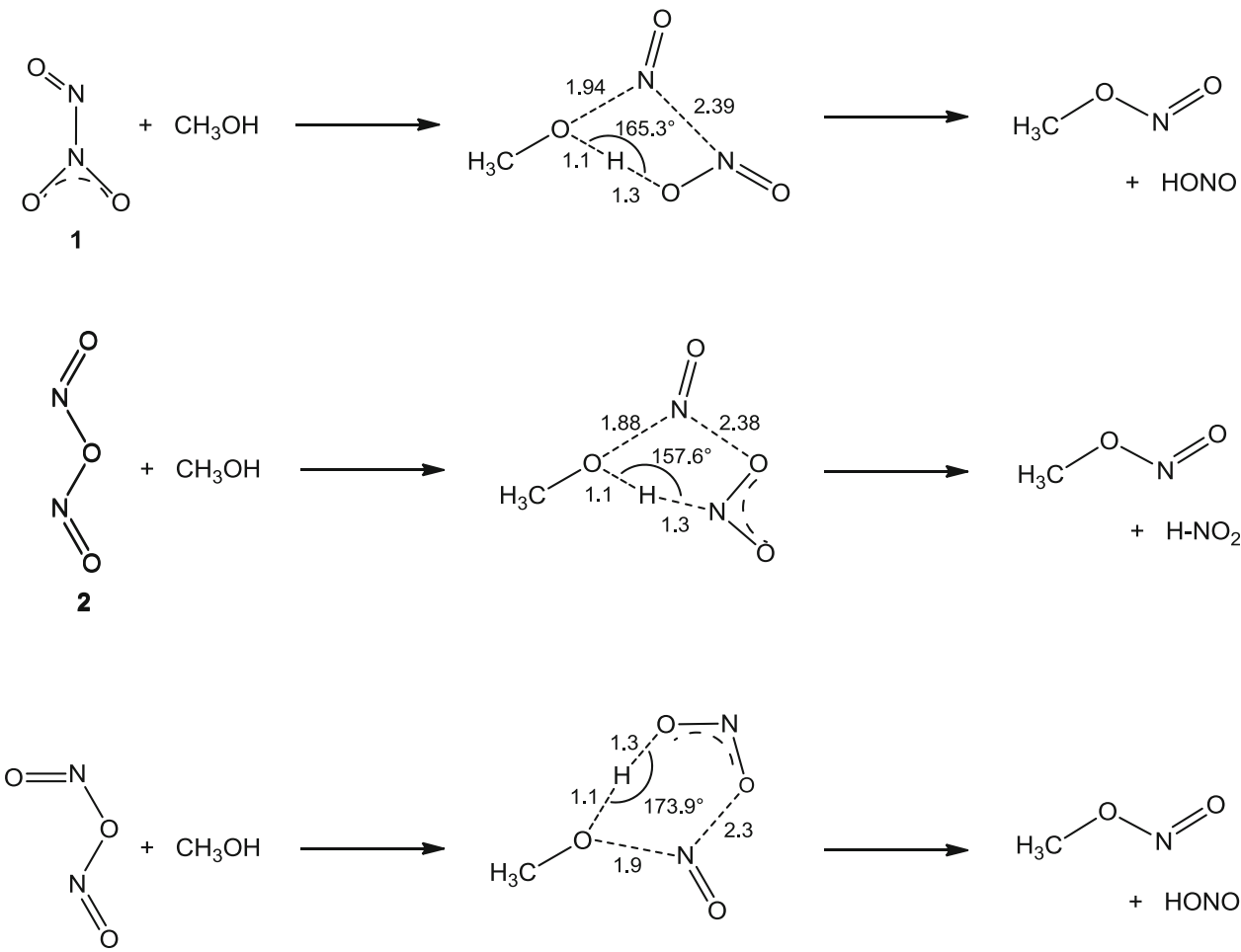

3

Table 2 Barrier for reaction of the $\mathrm{N}_{2} \mathrm{O}_{3}$ dimer species with methanol (see Scheme 4) at various levels of theory

\begin{tabular}{|c|c|c|c|c|c|c|}
\hline Structure & B3LYP & $\mathrm{CCSD}(\mathrm{T}) / / \mathrm{B} 3 \mathrm{LYP}$ & $\omega \mathrm{B} 97$ & $\operatorname{CCSD}(\mathrm{T}) / / \omega \mathrm{B} 97$ & CBS-APNO & $\mathrm{CCSD}(\mathrm{T}) / / \mathrm{QCISD}$ \\
\hline $\mathrm{N}_{2} \mathrm{O}_{3} \mathrm{I}$ & 6.1 & 8.45 & 9.0 & 9.4 & 9.4 & 10.45 \\
\hline $\mathrm{N}_{2} \mathrm{O}_{3} 2$ & 8.3 & 14.45 & 14.05 & 14.6 & 12.5 & 15.3 \\
\hline $\mathrm{N}_{2} \mathrm{O}_{3} \mathbf{3}$ & -1.1 & 1.9 & 2.0 & 3.8 & 2.9 & 5.0 \\
\hline
\end{tabular}

${ }^{a}$ Geometry optimized at QCISD/6-311++G(d,p) level; ZPE correction at B3LYP/6-311++G(df,pd) level single point energy calculation at $\operatorname{CCSD}(\mathrm{T}) / 6-311++\mathrm{G}(\mathrm{df}, \mathrm{pd})$ level

partition functions were calculated in order to estimate rate constants. As expected, the nitrosation reactions are characterized by a small pre-exponential rate factor of around $(2 \pm 1) \times 10^{5} \mathrm{M}^{-1} \mathrm{~s}^{-1}$, in line with the highly concerted mechanism. At $300 \mathrm{~K}$, a statistical TST-analysis predicts that about $96.5 \%$ of the $\mathrm{N}_{2} \mathrm{O}_{3}$ species react through its least stable isomer 3 (contributing to the $\mathrm{N}_{2} \mathrm{O}_{3}$ pool for less than $0.1 \%$ ). Isomer 1 would contribute for about $3.5 \%$ to the reactive flux, whereas the contribution of the symmetric isomer 2 (making up over $66 \%$ of the $\mathrm{N}_{2} \mathrm{O}_{3}$ pool) can be 
Scheme 5 Reaction of the $\mathrm{N}_{2} \mathrm{O}_{4}$ dimer species with methanol. Distances in Ångstrom and angles in degree as optimized at the QCISD/6$311++\mathrm{G}(\mathrm{d}, \mathrm{p})$ level of theory

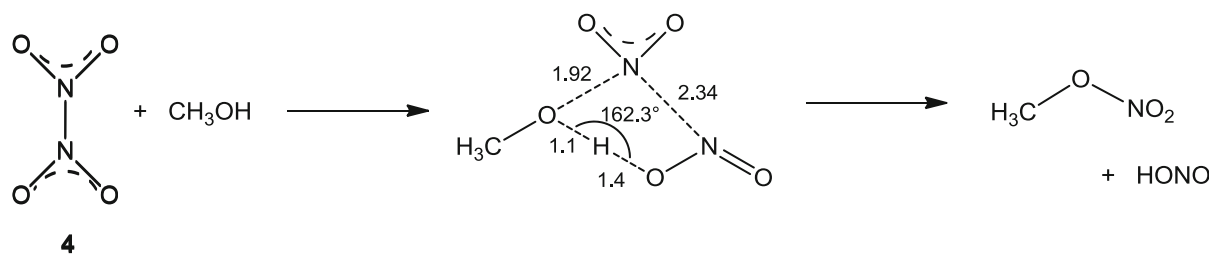<smiles>CO[N+](=O)[O-]</smiles>

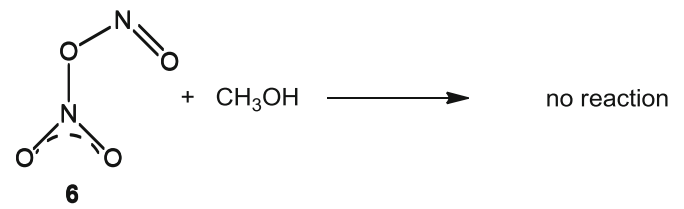

Table 3 Barrier for reaction of the $\mathrm{N}_{2} \mathrm{O}_{4}$ dimer species with methanol (see Scheme 4) at various levels of theory $\left(\mathrm{kcal} \mathrm{mol}^{-1}\right.$ )

\begin{tabular}{|c|c|c|c|c|c|c|}
\hline Structure & B3LYP & CCSD(T)//B3LYP & $\omega \mathrm{B} 97$ & $\mathrm{CCSD}(\mathrm{T}) / / \omega \mathrm{B} 97$ & CBS-APNO & $\overline{\mathrm{CCSD}(\mathrm{T}) / / \mathrm{QCISD}^{\mathrm{a}}}$ \\
\hline $\mathrm{N}_{2} \mathrm{O}_{4} 4$ & 24.7 & 27.1 & 29.1 & 28.3 & 29.4 & 29.25 \\
\hline $\mathrm{N}_{2} \mathrm{O}_{4} \mathbf{5}$ & 6.1 & -1.6 & 3.7 & 5.3 & 4.9 & 6.5 \\
\hline
\end{tabular}

a Geometry optimized at QCISD/6-311++G(d,p) level; ZPE correction at B3LYP/6-311++G(df,pd) level single point energy calculation at $\operatorname{CCSD}(\mathrm{T}) / 6-311++\mathrm{G}(\mathrm{df}, \mathrm{pd})$ level

neglected, even at $500 \mathrm{~K}$. In the temperature range of 200-500 K, the TST-predicted rate constants can be well represented by the Arrhenius expression $2.6 \times 10^{5} \mathrm{M}^{-1}$ $\mathrm{s}^{-1} \times \exp \left(-8.6 \mathrm{kcal} \mathrm{mol}^{-1} / \mathrm{R} T\right)$. At a methanol concentration of $0.045 \mathrm{M}$ (corresponding to 1 bar at $65{ }^{\circ} \mathrm{C}$, i.e. the boiling point of methanol), this implies an $\mathrm{N}_{2} \mathrm{O}_{3}$ lifetime of less than $3 \mathrm{~min}$ at $300 \mathrm{~K}$, or less than $0.5 \mathrm{~s}$ at $500 \mathrm{~K}$. This fast kinetics makes the experimental investigation of the reaction kinetics of this reaction very challenging and emphasizes the need for fast mixing in order to stay outside the mass-transfer regime.

Scheme 5 summarizes the reaction mechanisms of $\mathrm{N}_{2} \mathrm{O}_{4}$ with methanol. We emphasize the practical importance of this for the design and optimization of a process using alkyl nitrite as reactive intermediate. Indeed, only isomer $\mathbf{5}$ leads to the desired nitrite, whereas isomer $\mathbf{6}$ is unreactive and isomer $\mathbf{4}$ even leads to the formation of nitrate. The latter reaction is highly undesired as the nitrate species cannot decompose to regenerate the $\mathrm{NO}_{x}$ species (hence lowering the catalytic efficiency) and could lead to safety issues. Fortunately the computational predictions in Table 3 indicate that isomer $\mathbf{5}$ is significantly more reactive than isomer 4. On a practical level this implies that when $\mathrm{N}_{2} \mathrm{O}_{4}$ is formed it will still mainly form nitrite and not nitrate, despite the higher instability of isomer 5 relative to 4 . This suggests that one could work with an excess of $\mathrm{NO}_{2}$ (viz. $\mathrm{NO}_{2} / \mathrm{NO}>1$ ) in order to trap the HNO formed upon acidcatalyzed nitrite decomposition (See Scheme 2), without running into problems related to nitrate formation.

The difference in reactivity of the various $\mathrm{N}_{2} \mathrm{O}_{x}$ isomers is remarkable. Especially the substantial barrier predicted for $\mathrm{N}_{2} \mathrm{O}_{4}$ isomer 4 is particularly striking. To better understand what contributes to the activation barrier of such nitrosation reactions, we decided to split the activation energy into three terms as shown in Equation 1 and Fig. 3 .

$$
\begin{aligned}
E_{a c t}= & E\left(\mathrm{~N}_{2} \mathrm{O}_{\mathrm{x}}-\text { deform }\right) \\
& +E(\text { methanol }- \text { deform })-E(\text { stabilization })
\end{aligned}
$$

$E\left(\mathrm{~N}_{2} \mathrm{O}_{x}\right.$-deform) and $E$ (methanol-deform) represent the energy it takes to deform the two reactants from the free unconstrained forms to the geometry they adopt in the 


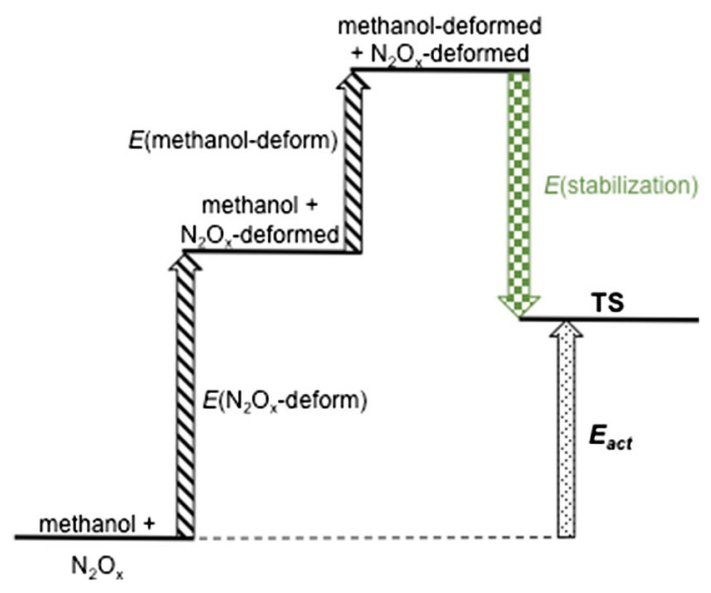

Fig. 3 Contribution of $\mathrm{N}_{2} \mathrm{O}_{x}$ and methanol deformation, and the stabilization energy on the activation barrier of $\mathrm{N}_{2} \mathrm{O}_{x}$ nitrosation reactions

transition state. $E$ (stabilization) is the attraction energy between the two deformed fragments in the transition state. As can be seen from the results summarized in Table 4, it takes substantially more energy to deform $\mathrm{N}_{2} \mathrm{O}_{4}$ than $\mathrm{N}_{2} \mathrm{O}_{3}$, due to substantial re-hybridization of the nitrogen atom(s). Moreover, the low dipole moment of the deformed $\mathrm{N}_{2} \mathrm{O}_{4}$ isomer 4 results in a very low stabilization energy for this particular reactant, explaining the exceptionally high barrier.

\subsection{Effect of the Alkyl Substituent}

The alkyl substituent $\mathrm{R}$ was found to have a negligible effect $\left(\leq 1 \mathrm{kcal} \mathrm{mol}^{-1}\right)$ on the reaction of $\mathrm{N}_{2} \mathrm{O}_{3}$ with various alcohols $\mathrm{ROH}$ as shown in Table 5. This indicates that the nitrosation reaction does barely differentiate
Table 5 Influence of the alcohol structure on the reactivity with $\mathrm{N}_{2} \mathrm{O}_{3}$ at the $\omega \mathrm{B} 97$ level of theory. $\Delta_{r} E_{x}$ and $E_{x}$ are the reaction energy and barrier associated with isomer $x$, respectively (in $\mathrm{kcal} \mathrm{mol}^{-1}$ )

\begin{tabular}{lrrrlll}
\hline Alcohol & $\Delta_{r} E_{1}$ & \multicolumn{1}{c}{$E_{1}$} & $\Delta_{r} E_{2}$ & $E_{2}$ & $\Delta_{r} E_{3}$ & $E_{3}$ \\
\hline Methanol & -8.9 & 9.0 & 0.4 & 14.05 & -12.1 & 2.0 \\
Ethanol & -8.6 & 9.0 & 0.7 & 14.2 & -11.8 & 2.2 \\
Isopropanol & -8.9 & 8.8 & 0.4 & 15.3 & -12.15 & 2.6 \\
$t$-Butanol & -8.1 & 10.5 & 1.2 & 14.7 & -11.3 & 5.35 \\
Benzyl alcohol & -8.5 & 8.0 & 0.8 & 13.3 & -11.7 & 1.75 \\
\hline
\end{tabular}

between primary, secondary and tertiary alcohols. In traditional oxidation systems, e.g. radical-mediated, substitution at the $\alpha$-position strongly activates the substrate, due to weakening of the $\alpha \mathrm{H}$-atom [38]. Although the substitution level does not seem to affect the nitrite formation mechanism, the subsequent acid-catalyzed decomposition was found to be rather sensitive on the stability of the corresponding carbonyl product (see Evans-Polanyi correlation between the decomposition barrier and reaction energy: $E_{\text {act }}=(12.1 \pm 0.1)+(0.15 \pm 0.01) \times \Delta_{r} E$ in kcal mol$\left.{ }^{-1}\right)$ [20].

Plotting the $\mathrm{N}_{2} \mathrm{O}_{3}$ nitrosation barriers versus the $\mathrm{O}-\mathrm{H}-\mathrm{X}$ angle in the TSs shows a remarkably linear trend (see Fig. 4). The more linear the TS, the easier the reaction proceeds as expected for a four-electron three-center process [39].

\subsection{Effect of the Solvent Polarity on the Nitrosation of isopropanol with $\mathrm{N}_{2} \mathrm{O}_{3}$}

Given the rather late TSs, i.e. featuring nearly fully dissociated $\mathrm{N}_{2} \mathrm{O}_{3}$ species (see Scheme 4), significant changes in solvation between the TS and the reactant state can be expected. This was investigated for the case of isopropanol

Table 4 Contribution of $\mathrm{N}_{2} \mathrm{O}_{x}$ and methanol deformation on the methanol nitrosation barrier

\begin{tabular}{|c|c|c|c|c|c|c|}
\hline & $\begin{array}{l}E_{a c t} \\
\left(\mathrm{kcal} \mathrm{mol}^{-1}\right)\end{array}$ & 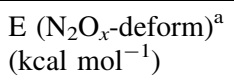 & $\begin{array}{l}\text { Dipole }\left(\mathrm{N}_{2} \mathrm{O}_{x^{-}}\right. \\
\text {deform) (Debye) }\end{array}$ & $\begin{array}{l}\text { E (methanol-deform) }{ }^{\mathrm{a}} \\
(\mathrm{kcal} \text { mol-1) }\end{array}$ & $\begin{array}{l}\text { Dipole (methanol- } \\
\text { deform) (Debye) }\end{array}$ & $\begin{array}{l}\text { E (stabilization) } \\
\left(\mathrm{kcal} \mathrm{mol}^{-1}\right)\end{array}$ \\
\hline $\begin{array}{c}\mathrm{N}_{2} \mathrm{O}_{3} \\
\mathbf{1}\end{array}$ & 10.45 & 18.8 & 9.27 & 9.5 & 2.08 & 17.9 \\
\hline $\begin{array}{c}\mathrm{N}_{2} \mathrm{O}_{3} \\
2\end{array}$ & 15.3 & 23.2 & 10.34 & 13.4 & 2.12 & 21.3 \\
\hline $\begin{array}{c}\mathrm{N}_{2} \mathrm{O}_{3} \\
\mathbf{3}\end{array}$ & 5.0 & 16.7 & 8.68 & 9.8 & 2.09 & 21.5 \\
\hline $\begin{array}{c}\mathrm{N}_{2} \mathrm{O}_{4} \\
\mathbf{4}\end{array}$ & 29.25 & 30.5 & 6.02 & 5.8 & 2.06 & 7.0 \\
\hline $\begin{array}{c}\mathrm{N}_{2} \mathrm{O}_{4} \\
\mathbf{5}\end{array}$ & 6.5 & 25.7 & 11.48 & 6.1 & 2.08 & 25.3 \\
\hline
\end{tabular}

Geometry optimized at QCISD/6-311++G(d,p) level; ZPE correction at B3LYP/6-311++G(df,pd) level single point energy calculation at $\operatorname{CCSD}(\mathrm{T}) / 6-311++\mathrm{G}(\mathrm{df}, \mathrm{pd})$ level

${ }^{\text {a }}$ The deformed $\mathrm{N}_{2} \mathrm{O}_{x}$ and methanol fragments were taken from the optimized TS and separated at infinite distance without further optimization 


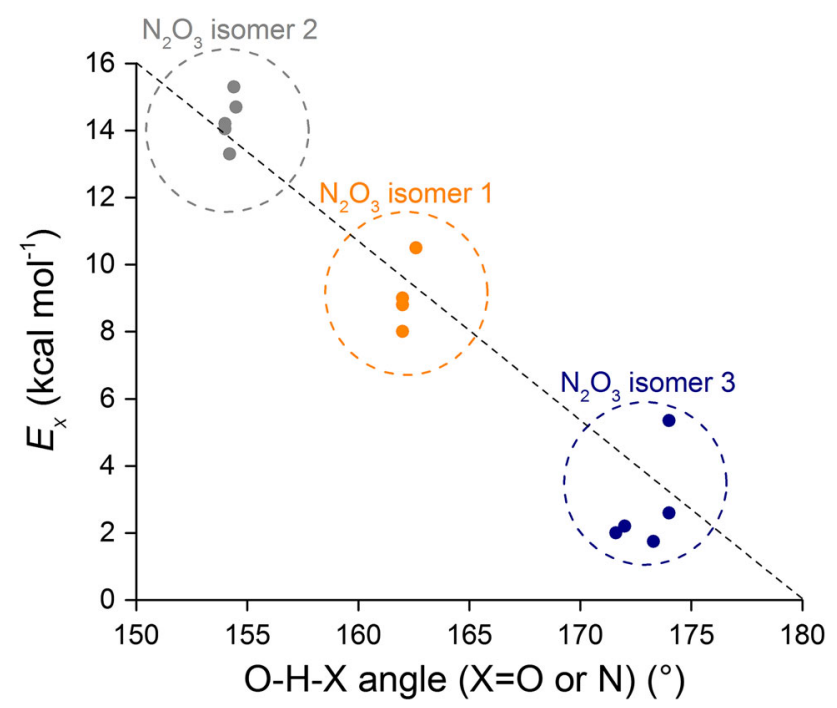

Fig. 4 Linear trend of the $\mathrm{N}_{2} \mathrm{O}_{3}$ nitrosation barrier with methanol with the $\mathrm{O}-\mathrm{H}-\mathrm{X}$ angle at the $\omega \mathrm{B} 97$ level of theory

Table 6 Decrease in adiabatic barrier (in $\mathrm{kcal} \mathrm{mol}^{-1}$ ) as predicted by the Polarizable Continuum Model at the $\omega \mathrm{B} 97$ level of theory for various solvents ( $\varepsilon$ is the dielectrical constant)

\begin{tabular}{lcccc}
\hline & $\varepsilon$ & Isomer $\mathbf{1}$ & Isomer 2 & Isomer 3 \\
\hline Vacuum & 1 & 0 & 0 & 0 \\
Argon & 1.43 & -0.26 & -1.09 & -0.60 \\
1-hexene & 2.07 & -0.60 & -2.17 & -1.23 \\
Dibutylether & 3.05 & -1.00 & -3.12 & -1.87 \\
Dichloroethane & 10.12 & -2.09 & -5.11 & -3.00 \\
2-propanol & 19.26 & -2.43 & -5.70 & -3.30 \\
Acetonitrile & 35.69 & -2.60 & -6.02 & -3.70 \\
\hline
\end{tabular}

at the $\omega \mathrm{B} 97$ level of theory. It was found that the gas phase dipole moments of the three $\mathrm{N}_{2} \mathrm{O}_{3}$ isomers $\mathbf{1}, \mathbf{2}$ and $\mathbf{3}$ equal 2.26, 0.55 and 0.41 Debye, respectively. On the other hand, the gas phase dipole moments of the corresponding nitrosation TSs equal 5.68, 6.39 and 5.57 Debye, respectively. The largest change in dipole moment is therefore predicted for the symmetric isomer $\mathbf{2}$. The polarizable continuum model (PCM) [40] indeed predicts a significant decrease in the effective barrier as the solvent polarity increases (Table 6), the largest effect being observed for isomer $\mathbf{2}$. This effect can be visualized in the Kirkwood plot displayed in Fig. 5.

As a consequence of this solvent effect, the reactivity of $\mathrm{N}_{2} \mathrm{O}_{3}$ will even increase in the liquid phase, and the relative contribution of the various isomers to the reactive flux is slightly changing. As an example, focusing on isopropanol as a solvent, isomer $\mathbf{1}$ will contribute for more than $90 \%$ of

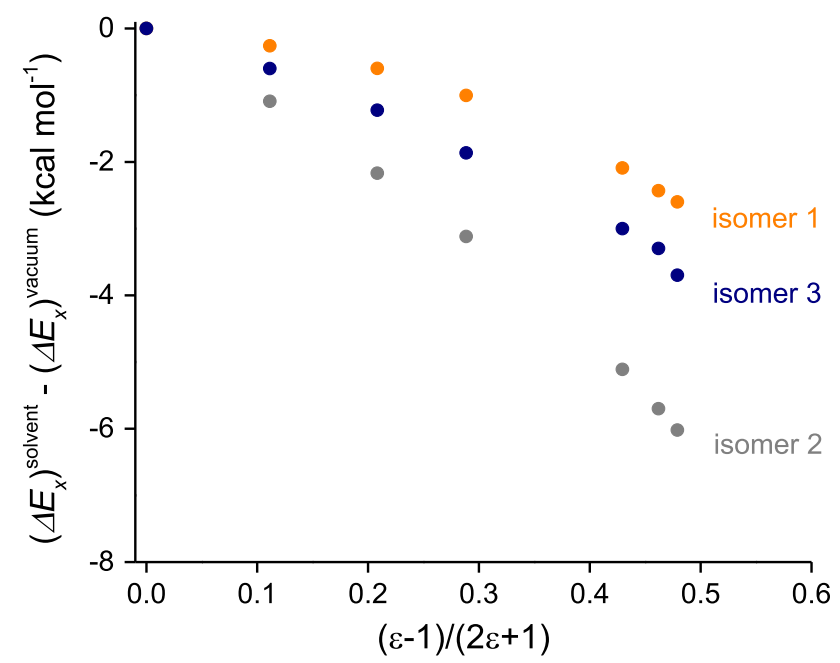

Fig. 5 Kirkwood plot showing the decrease of the adiabatic nitrosation barrier for the three $\mathrm{N}_{2} \mathrm{O}_{3}$ isomers as a function of the solvent polarity ( $\varepsilon$ being the dielectrical constant)

the $\mathrm{N}_{2} \mathrm{O}_{3}$ population (due to its large dipole moment it is much more stabilized in a solvent than in vacuum), followed by isomer $2(8 \%)$; the contribution of isomer $\mathbf{3}$ stays below $5 \%$, even at $500 \mathrm{~K}$. On the other hand, the contribution of the different isomers to the reaction flux also changes to: $28.6,0.1$ and $71.3 \%$, respectively. The $\mathrm{N}_{2} \mathrm{O}_{3}$ lifetime drops from about $3 \mathrm{~min}$ in vacuum to less than $100 \mathrm{~ms}$ in isopropanol (assuming an alcohol concentration of $0.045 \mathrm{M}$ and $300 \mathrm{~K}$ ). From a practical point of view, these predictions hence suggest a much higher rate (resulting in a higher throughput) in the liquid phase than the gas phase. In the temperature range of $200-500 \mathrm{~K}$, the TST-predicted rate constants can be expresses by the Arrhenius equation $5.3 \times 10^{6} \mathrm{M}^{-1} \mathrm{~s}^{-1} \times \exp (-5.75 \mathrm{kcal}$ $\left.\mathrm{mol}^{-1} / \mathrm{R} T\right)$. We emphasize that not only the activation energy is predicted to decrease (by about almost $3 \mathrm{kcal} \mathrm{mol}^{-1}$ ), but that also the pre-exponential factor is increase by a factor 20 , due to the confinement in the solvent spheres, lowering the partition functions. For a bimolecular reaction, this results in an increase in TST-prefactor.

\section{Conclusions}

Quantum chemical calculations demonstrate that the various isomers of $\mathrm{N}_{2} \mathrm{O}_{3}$ and $\mathrm{N}_{2} \mathrm{O}_{4}$ react readily with alcohols to form the corresponding alkyl nitrite. Calculations also predict, that even with $\mathrm{N}_{2} \mathrm{O}_{4}$ the formation of methyl nitrate will be negligible compared to the formation of methyl nitrite. The precise structure of the alcohol was found to have a negligible effect on the nitrosation 
reaction. On the other hand, (polar) solvents were found to speed up the reaction, both through an enhancement of the pre-exponential factor, and a reduction of the barrier height.

Acknowledgments IH acknowledges financial support from the ETH Zurich and the Swiss National Science Foundation.

\section{References}

1. Rebsdat S, Mayer D (2011) Ethylene Oxide, Ullmann's Encyclopedia of Industrial Chemistry. Wiley, Weinheim

2. Umemura S, Miyazaki H (1984) Kagaku Kogyo 35:34

3. Uchiumi SI, Ataka K, Matsuzaki T (1999) J Organomet Chem $576: 279$

4. Uchiumi SI, Ataka K (2002) Handbook of Organopalladium Chemistry for Organic Synthesis. Wiley, New York, pp 2691-2704

5. Fang D, Ying W (1993) Huaxue Shijie 34:583

6. He L, Xiao H, Li Y (2006) Gongye Cuihua 14:11

7. Wu L (2008) Shanghai Huagong 33:18

8. Ma Z, Meng X, Wang H, Zhou W, Jiang H (2009) Shiyou Huagong 38:456

9. Zhou J, Liu X, Liu D (2009) Huagong Jinzhan 28:47

10. Wang J, Yang W, Lu J (2009) Huagong Jinzhan 28:1216

11. Boswell C (2012) ICIS Chem Bus 281(5):32-33

12. Hantzsch A (1901) Chem Ber 36:2097

13. Langenbeck W, Richter M (1956) Chem Ber 89:202

14. Niki H, Maker PD, Savage CM, Breitenbach LP (1982) Intern J Kinetics 14:1199

15. Koda S, Yoshikawa K, Okada J, Akita K (1985) Environ Sci Technol 19:262

16. Liu G, Ji Y, Li W (2010) Chem Eng J 157:483

17. Wang H, Li G (2010) Chem Eng J 163:422

18. Ji Y, Zhang B, Liu G, Li W, Xiao W (2010) Tianranqi Huagong $35: 12$

19. (a) US 4353843 and references therein; (b) US2831882; (c) DE1156775; (d) US1691302; (e) US4467109; (f) US 4229589; (g) EP1346976; (h) CN102008922; (i) CN201711149

20. Aellig C, Neuenschwander U, Hermans I (2012) ChemCatChem 4:525
21. Aellig C, Girard C, Hermans I (2011) Angew Chem Int Ed 50:12355

22. Aellig C, Scholz D, Hermans I (2012) ChemSusChem 9:1732

23. Liu Y-D, Zhong RG (2010) Chin J Str Chem 29(3):421

24. Sun Z, Liu YD, Lv CL, Zhong RG (2009) J Mol Structure 908:107

25. Liu W-G, Goddard WA (2012) J Am Chem Soc 134:12970

26. Frisch MJ, Trucks GW, Schlegel HB, Scuseria GE, Robb MA, Cheeseman JR, Scalmani G, Barone V, Mennucci B, Petersson GA, Nakatsuji H, Caricato M, Li X, Hratchian HP, Izmaylov AF, Bloino J, Zheng G, Sonnenberg JL, Hada M, Ehara M, Toyota K, Fukuda R, Hasegawa J, Ishida M, Nakajima T, Honda Y, Kitao O, Nakai H, Vreven T, Montgomery JA, Peralta JE, Ogliaro F, Bearpark M, Heyd JJ, Brothers EE, Kudin KN, Staroverov VN, Kobayashi R, Normand J, Raghavachari K, Rendell A, Burant JC, Iyengar SS, Tomasi J, Cossi M, Rega N, Millam JM, Klene M, Knox JE, Cross JB, Bakken V, Adamo C, Jaramillo J, Gomperts R, Stratmann RE, Yazyev O, Austin AJ, Cammi R, Pomelli C, Ochterski JW, Martin RL, Morokuma R, Zakrzewski VG, Voth GA, Salvador P, Dannenberg JJ, Dapprich S, Daniels AD, Farkas O, Foresman JB, Ortiz JV, Cioslowski J, Fox DJ (2009) Gaussian 09, Revision A.02. Gaussian Inc., Wallingford

27. Becke AD (1992) J. Chem. Phys. 96:2155

28. Becke AD (1992) J Chem Phys. 97:9173

29. Becke AD (1993) J Chem Phys. 98:5648

30. Chai JD, Head-Gordon M (2008) J Chem Phys. 128:084106

31. Pople JA, Head-Gordon M, Raghavachari K (1987) J Chem Phys. 87:5968

32. Ochterski JW, Petersson GA, Montgomery JA Jr (1996) J Chem Phys. 104:2598

33. Bartlett RJ, Purvis GD III (1978) Int J Quantum Chem 14:561

34. Pople JA, Krishnan R, Schlegel HB, Binkley JS (1978) Int J Quantum Chem 14:545

35. Varetti EL, Pimentel GC (1971) J Chem Phys. 55:3813

36. Nour EM, Chen LH, Laane J (1983) J Phys Chem 87:1113

37. Holland RF, Maier WB, Ii J (1983) Chem Phys 78:2928

38. Hermans I, Nguyen TL, Jacobs PA, Peeters J (2005) ChemPhysChem 6:637

39. Albright TA, Burdett JK, Whangbo M-H (1985) Orbital Interactions in Chemistry. Wiley, Hoboken

40. Tomasi J, Mennucci B, Cammi R (2005) Chem Rev 105:2999 